\title{
From the Ganglioside GQ1b $\alpha$ to Glycomimetic Antagonists of the Myelin-Associated Glycoprotein (MAG)
}

\author{
Beat Ernst*, Oliver Schwardt, Stefanie Mesch, Matthias Wittwer, Gianluca Rossato, and \\ Angelo Vedani
}

\begin{abstract}
Dedicated to Professor Daniel Belluš on the occasion of his 70th birthday
Abstract: The tetrasaccharide 4 , a substructure of ganglioside GQ1b $\alpha$, shows a remarkable affinity for the myelinassociated glycoprotein (MAG) and was therefore selected as starting point for a lead optimization program. In our search for structurally simplified and pharmacokinetically improved mimics of 4, antagonists with modifications of the core disaccharide Gal $\beta(1-3)$ GalNAc, as well as the terminal $\alpha(2-3)$ - and the internal $\alpha(2-6)$-linked neuraminic acid were synthesized and tested in target-based binding assays. Compared to the reference tetrasaccharide $\mathbf{4}$, the most potent antagonist $\mathbf{1 7}$ exhibits a 360-fold improved affinity. Furthermore, pharmacokinetic parameters such as stability in the cerebrospinal fluid, $\log \mathrm{D}$ and permeation through the BBB indicate the drug-like properties of antagonist 17.
\end{abstract}

Keywords: Docking $\cdot$ Hapten inhibition assay $\cdot$ Homology model $\cdot$ Gangliosides ·

Myelin-associated glycoprotein (MAG) · MAG antagonists · Surface plasmon resonance (Biacore)

\section{Introduction}

The injured adult mammalian central nervous system (CNS) lacks the ability for axon regeneration, ${ }^{[1,2]}$ predominantly due to specific inhibitors expressed on residual myelin and on astrocytes recruited to the site of injury. ${ }^{[3-7]}$ Several inhibitor proteins have been identified, one of them being the myelin-associated glycoprotein (MAG). ${ }^{[8]}$ MAG is a transmembrane glycoprotein ${ }^{[9]}$ belonging to the so-called Siglecs, a family of the sialic acid-binding immunoglobulin like lectins. ${ }^{[10,11]}$ On the surface of neurons, MAG interacts with two classes of targets: Proteins of the family of Nogo receptors $(\mathrm{NgR})^{[12,13]}$ and brain gangliosides (GD1a and GT1b) ${ }^{[11,14-16]}$ (Fig. 1). Although the relative roles of gangliosides and $\mathrm{NgRs}$ as MAG ligands have yet to be resolved, ${ }^{[8,17]}$ in some systems, MAG inhibition is completely reversed by sialidase treatment, suggesting that MAG uses sialylated glycans

${ }^{\star}$ Correspondence: Prof. Dr. B. Ernst

Institut für Molekulare Pharmazie

Pharmazentrum der Universität Basel

Klingelbergstrasse 50

$\mathrm{CH}-4056$ Basel

Tel.: + 41612671551

Fax: + 41612671552

E-mail: beat.ernst@unibas.ch as its major axonal ligands. ${ }^{[18]}$ Therefore, blocking MAG with potent glycomimetic antagonists may be a valuable therapeutic approach to enhance axon regeneration.

Schnaar and coworkers ${ }^{[19]}$ reported that a limited set of structurally related gangliosides like GT1b or GQ1ba (Fig. 2), known to be expressed on myelinated neurons in vivo, are functional ligands for MAG. Recently, the MAG-affinity of a partial structure of GQ1bo, the tetrasaccharide 2 , could clearly be correlated with its ability to reverse MAG-mediated inhibition of axonal outgrowth. ${ }^{[22]}$ Since SAR studies indicate that not only the terminal, $\alpha(2-3)$-linked, but also the internal, $\alpha(2-6)$-linked sialic acid is essential for MAG binding, various partial structures of $\mathbf{1}^{[20]}$ as well as sulfated analogs, e.g. $\mathbf{3}^{[21]}$ were synthesized.

\section{Design of Glycomimetics}

High-affinity MAG antagonists with concurrent drug-like pharmacokinetic properties would provide a valuable tool for the investigation of the exact physiological role of MAG in the inhibitory cascade leading to the collapse of growth cones, the reason for the failure of regeneration of injuries in the CNS. Because of the shallow binding site typically present in lectins, carbohydrate ligands often exhibit only modest, i.e. milli- to micromolar affinities. ${ }^{[23]}$ This also proved true for MAG with a 180 micromolar affinity for tetrasaccharide 4, the binding epitope of GQ1b $\alpha$
(Fig. 3).[24] In addition to the therefore required improvement of affinity, pharmacokinetic issues as metabolic stability, e.g. sialidase stability ${ }^{[26]}$ or permeation of the blood brain barrier have also to be addressed. For the in vivo application, it is planned to add the antagonist by infusion to the site of injury. Therefore, a prolonged stability in the cerebrospinal fluid is also required. Furthermore, to maintain the necessary minimal therapeutic concentration in the CNS, a loss of the antagonist by an active or passive transport mechanism would be detrimental.

In a first approach, we focused on a reduction of the structural complexity of GQ1b $\alpha$ (1) and, at the same time, an improvement of pharmacodynamic and pharmacokinetic properties. From various structure-affinity relationship studies (SAR), ${ }^{[27,28]}$ the tetrasaccharide 4 was identified as the minimal carbohydrate epitope. Detailed binding information of epitope 4 was obtained by STD NMR experiments $^{[24]}$ (Fig. 3). They indicated important lipophilic interactions of the glycerol side chain of the $\alpha(2-3)$-linked $N$-acetyl neuraminic acid (Neu5Ac), the $\beta$-face of the galactose moiety and the $N$ acetates of both Neu5Ac residues. In addition, the carboxylates of the two Neu5Ac moieties are involved in salt bridges and the $\mathrm{C}(9)-\mathrm{OH}$ of the $\alpha(2-3)$-linked Neu5Ac is forming a relevant hydrogen bond. ${ }^{[25]} \mathrm{A}$ verification of these findings by docking studies to a homology model of MAG ${ }^{[29,30]}$ revealed the corresponding amino acids 


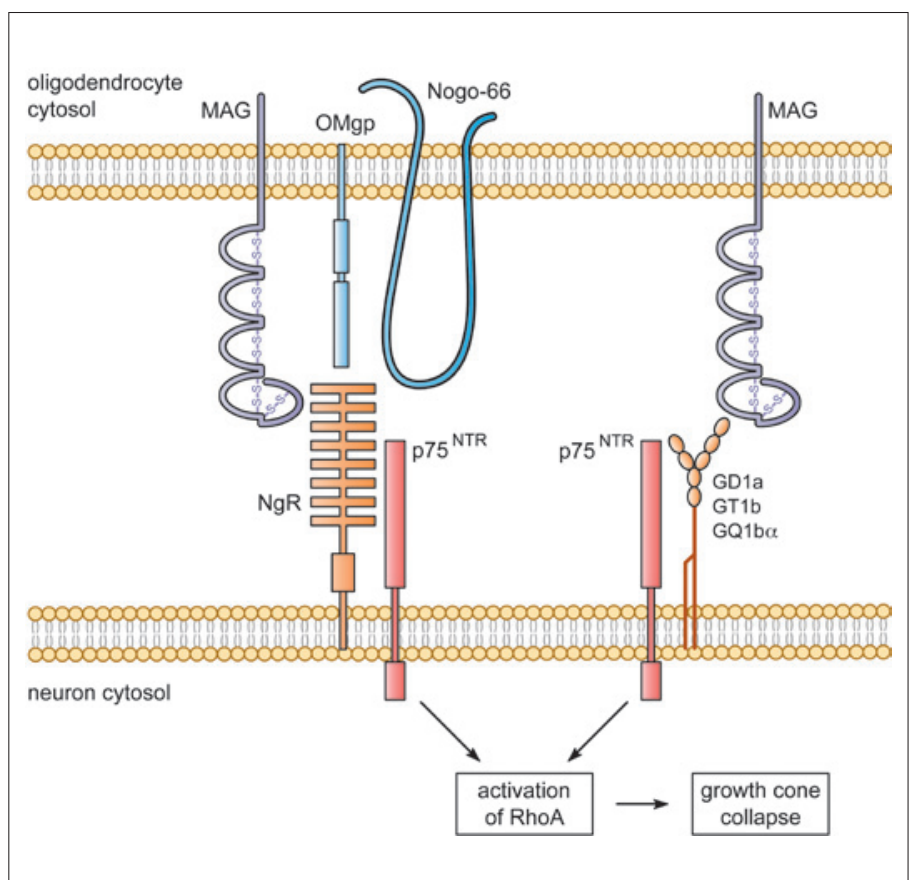

Fig. 1. Myelin-associated glycoprotein (MAG), Nogo 66 and oligodendrocyte myelin glycoprotein (OMgp) bind to the Nogo receptor (NgR). Via the neurotrophin receptor p $75^{\mathrm{NTR}}$, the inhibitory signal is transduced into the cytosol of the neuron. MAG also binds to the gangliosides GD1a and GT1b. Again, with co-receptor p75 NTR, the inhibitory signal is transduced into the cytosol. Intracellularly, the small GTPase RhoA is activated, which leads to a collapse of the growth cones of the injured axon (adapted from Filbin et al. ${ }^{[5]}$ ).

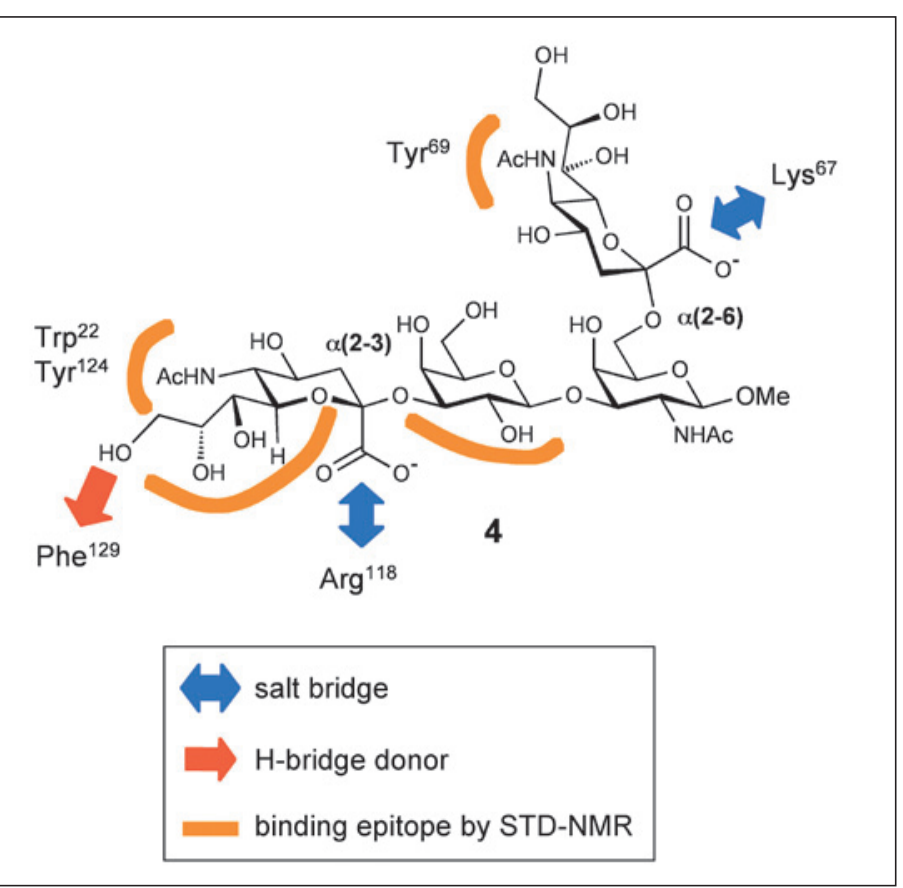

Fig. 3. Binding epitope of tetrasaccharide 4 as determined by STD NMR. ${ }^{[24]}$ Besides two salt bridges by the carboxylates of the Neu5Ac moieties and an important hydrogen bond donated by the $\mathrm{C}(9)-\mathrm{OH}$ of the $\alpha(2-3)$-linked Neu5Ac, ${ }^{[25]}$ the binding epitope involves lipophilic interactions of the glycerol side chain of the $\alpha(2-3)$-linked Neu5Ac, the $\beta$-face of the galactose moiety and the $N$-acetates of the Neu5Ac residues. forming the binding site (Figs 3 and 6). Based on this information, a rational approach for the design of MAG antagonists was envisaged.

\section{Replacement of the Galß(1-3)GalNAc Core}

In a first approach, the $\mathrm{Gal} \beta(1-3)$ GalNAc core, establishing a lipophilic contact with MAG, ${ }^{[24]}$ was replaced by biphenyl $(\boldsymbol{\rightarrow 5})$, which acts as a linker to position the carboxylates of the two
Neu5Ac moieties in the appropriate spatial orientation (Fig. 4). In addition, the biphenyl linker enables a lipophilic contact with the binding site and at the same time reduces the high polarity of the lead structure 4. Starting from glycosyl donor 6, ${ }^{[37]}$ the building blocks 7 and 8 were synthesized, permitting the formation of the protected test compound 9 by Suzuki coupling in an excellent yield (Scheme 1). Mimic 5 was obtained after deprotection under Zemplén conditions and showed a four-fold reduction of affinity compared to tetrasaccharide 4[36] (Table 1). For an additional structural simplification, the $\alpha(2-6)$-linked Neu5Ac moiety was replaced by acetic acid leading to antagonist 10, which showed a slightly lower affinity than 5. To further fine-tune the spatial orientation of the carboxylates, the biphenyl linker was replaced by a 1,2,3-triazol4-yl-phenyl moiety, a modification with practically no influence on the affinity for MAG. [38]

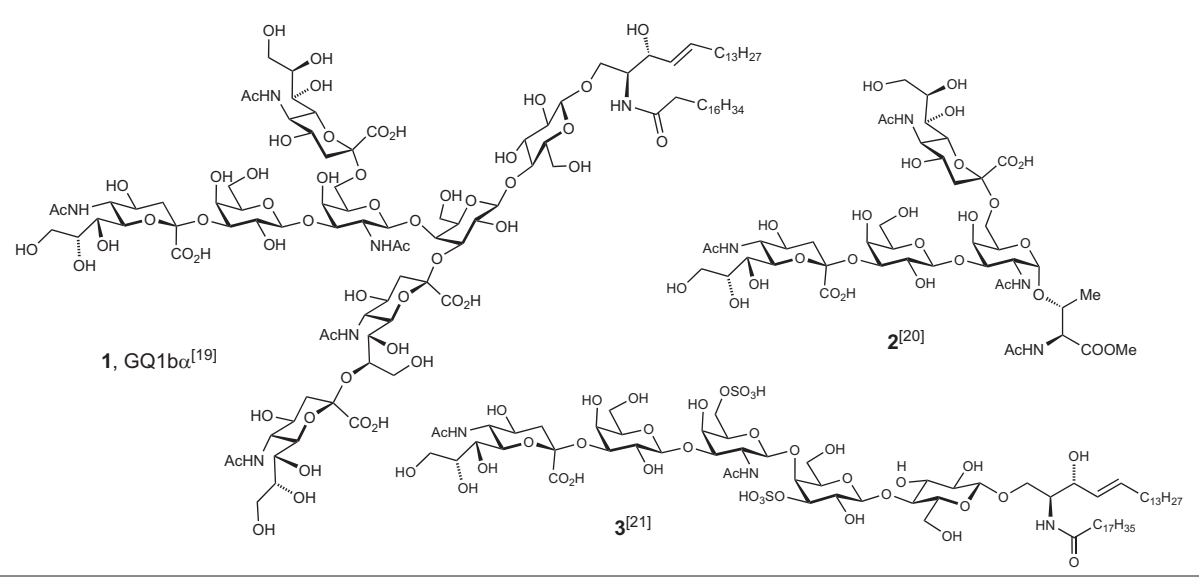

Fig. 2. GQ1b $\alpha(1)^{[19]}$ and partial structures thereof. ${ }^{[20,21]}$ Since the reported affinity data were obtained in different assay formats, they should be compared with caution. For binding of MAGtransfected COS cells to immobilized ganglioside 1 or to the disulfated GM1b analog 3, apparent $\mathrm{K}_{\mathrm{D}} \mathrm{s}$ of 38 and $7.4 \mathrm{pmol} /$ well were reported. ${ }^{[21]}$ In a competitive binding assay with tetrasaccharide 2, an $\mathrm{IC}_{50}$ of $300 \mathrm{nM}$ was determined. ${ }^{[20]}$

\section{Lipophilic Substituents on the $\alpha(2-3)-$ linked Sialic Acid}

A pivotal simplification of the tetrasaccharide lead structure 4 was reported by Kelm and Brossmer who modified the $\alpha(2-$ 3)-linked sialic acid in the 2-, 5- or 9-position to obtain up to a ten-fold enhancement of affinity compared to lead 4. ${ }^{[28,39,40]}$ Further optimization of these three positions led to antagonist 17 (Scheme 2) with a 360-fold improved affinity, i.e. 500 nanomolar. [25,41]

Starting from the Boc-protected neuraminic acid derivative 12,[41] 14 was obtained by deprotection with TMSCl and $\mathrm{PhOH}(\rightarrow 13)$ followed by acylation with fluoroacetyl chloride. Glycosylation using 2,3-difluorobenzyl alcohol $(\boldsymbol{\rightarrow} \mathbf{1 5})$, amidation using modified Staudinger conditions $^{[42]}(\rightarrow 16)$ and final deprotection gave the test compound 17. 

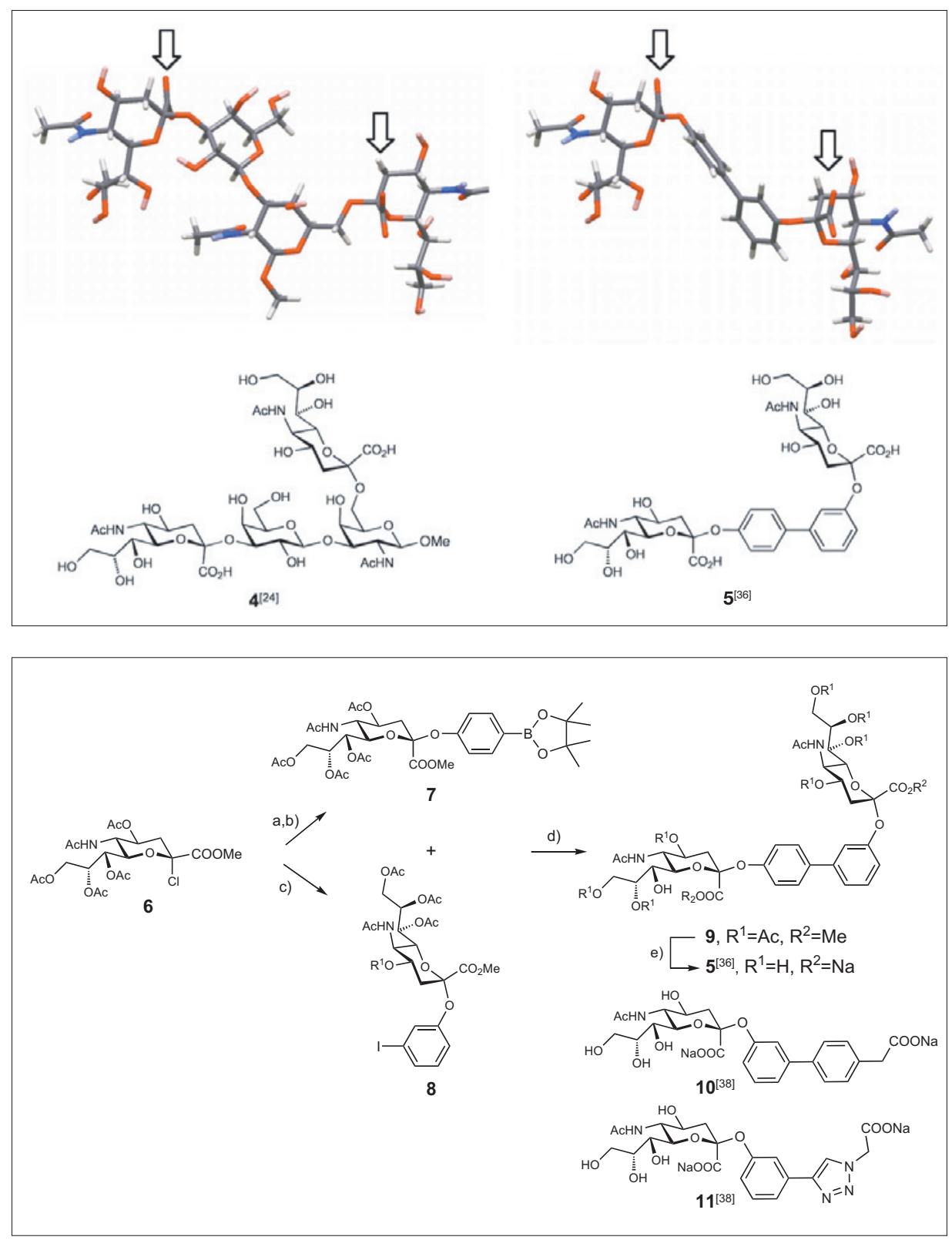

\section{Lipophilic and Hydrophilic Replacements of the $\alpha(2-6)-$ linked Sialic Acid}

Since the carboxylate of the $\alpha(2-6)$ linked Neu5Ac in tetrasaccharide $\mathbf{4}$ forms a salt bridge with Lys67 and the $N$-acetate a lipophilic contact with Tyr69 (Figs 3 and 6A), hydrophilic as well as lipophilic substitutes were explored. A replacement by lactic acid $(\mathbf{\rightarrow 2 2})$ or biphenylmethyl $(\mathbf{\rightarrow 2 3})$ yielded affinities in the range of tetrasaccharide 4 (Scheme 3). Combined with the most successful modification of the 9-position of the $\alpha(2-3)$-linked Neu5Ac (Scheme 2) antagonist 29 with low micromolar affinity could be identified (Scheme 4).[30]

\section{Biological Evaluation}

\section{Determination of Affinity for MAG}

For the evaluation of the binding properties of these new MAG antagonists two
Fig. 4. Replacement of the Galß(1-3)GalNAc core of 4 by a biphenyl $(\rightarrow 5)$ leads to only marginal changes of the required spatial orientation of the carboxylate of the $\alpha(2-$ 6)-linked Neu5Ac, but results in a four-fold reduction in affinity. ${ }^{[36]}$

Scheme 1. a) 4-Bromophenol, BnNEt ${ }_{3} \mathrm{Br}$, aq. $\mathrm{NaOH} / \mathrm{DCM}, 40{ }^{\circ} \mathrm{C}, 2.5 \mathrm{~h}, 56 \%$; b) bis(picanolato)diborane, $\mathrm{KOAc}, \mathrm{PdCl}_{2}$ (dppf), dppf, dioxane, MW $120^{\circ} \mathrm{C}$, $45 \mathrm{~min}, 85 \%$; c) 3-iodophenol, BnNEt 3 Br, aq. NaOH/DCM, 40 ${ }^{\circ} \mathrm{C}, 2.5 \mathrm{~h}, 46 \%$; d) $\mathrm{Ag}_{2} \mathrm{CO}_{3}, \mathrm{Pd}\left(\mathrm{PPh}_{3}\right)_{4}$, dioxane, MW $120^{\circ} \mathrm{C}, 7$ h, $77 \%$; e) i. $\mathrm{NaOMe}, \mathrm{MeOH}$, r.t., 17 h, ii. aq. $\mathrm{NaOH}$, r.t., 6 h, iii. Dowex $50 \times 8$ $\left(\mathrm{Na}^{+}\right), 56 \%$.

For the $K_{D}$ determination in the $\mathrm{Bi}$ assay formats were applied; a fluorescent hapten binding assaye[43] and a surface plasmon resonance based biosensor (Biacore) experiment ${ }^{[30,41]}$ (Fig. 5). For the hapten inhibition assay, a recombinant protein consisting of the three $N$-terminal domains of MAG and the Fc part of human IgG $\left(\mathrm{MAG}_{d 1-3}-\mathrm{Fc}\right)$ was produced by expression in $\mathrm{CHO}$ cells and affinity purification on protein A-agarose ${ }^{[43]}$ (Fig. 5A). The relative inhibitory concentrations $\left(\mathrm{rIC}_{50}\right)$ of the test compounds as competitive ligands were determined in microtiter plates coated with fetuin as binding target for $\mathrm{MAG}_{d 1-3}-\mathrm{Fc}$. By complexing the Fc-part with alkaline phosphataselabeled anti-Fc antibodies and measuring the initial velocity of fluorescein release from fluorescein diphosphate, the amount of bound $\mathrm{MAG}_{d 1-3}-\mathrm{Fc}$ can be determined. The affinities were measured relative to the reference compound $\mathbf{4}\left(\mathrm{rIC}_{50}\right.$ of $\mathbf{1}$, Table 1). acore assay, $\mathrm{MAG}_{d 1-3}-\mathrm{Fc}$ could not be immobilized by amine coupling, because three lysines are positioned in proximity to the carbohydrate binding site (Fig. 5B). Therefore, $\mathrm{MAG}_{d 1-3}-\mathrm{Fc}$ was immobilized on a dextran chip containing a surface of covalently bound protein A. A reference cell providing only protein A was used to compensate unspecific binding to the matrix (Figs 5C and 5D).

\section{Stability in Cerebrospinal Fluid}

For nerve regeneration, MAG antagonists will most likely be applied to the CNS by a local infusion. We therefore tested the stability of the fluoroacetate $\mathbf{1 7}$ in artificial cerebrospinal fluid (aCSF) ${ }^{[44]}$ for $19 \mathrm{~h}$ at $37{ }^{\circ} \mathrm{C}$ and, as a control, in buffer solution. According to LC-MS analysis, more than $95 \%$ of the initial concentrations of 17 were recovered from both media, predicting a high stability in the CNS, the 
Table 1. Relative inhibitory concentrations $\left(\mathrm{rlC}_{50}\right)$ of MAG antagonists, $\mathrm{K}_{\mathrm{D}}$ values of compounds 4, 17 and 29.

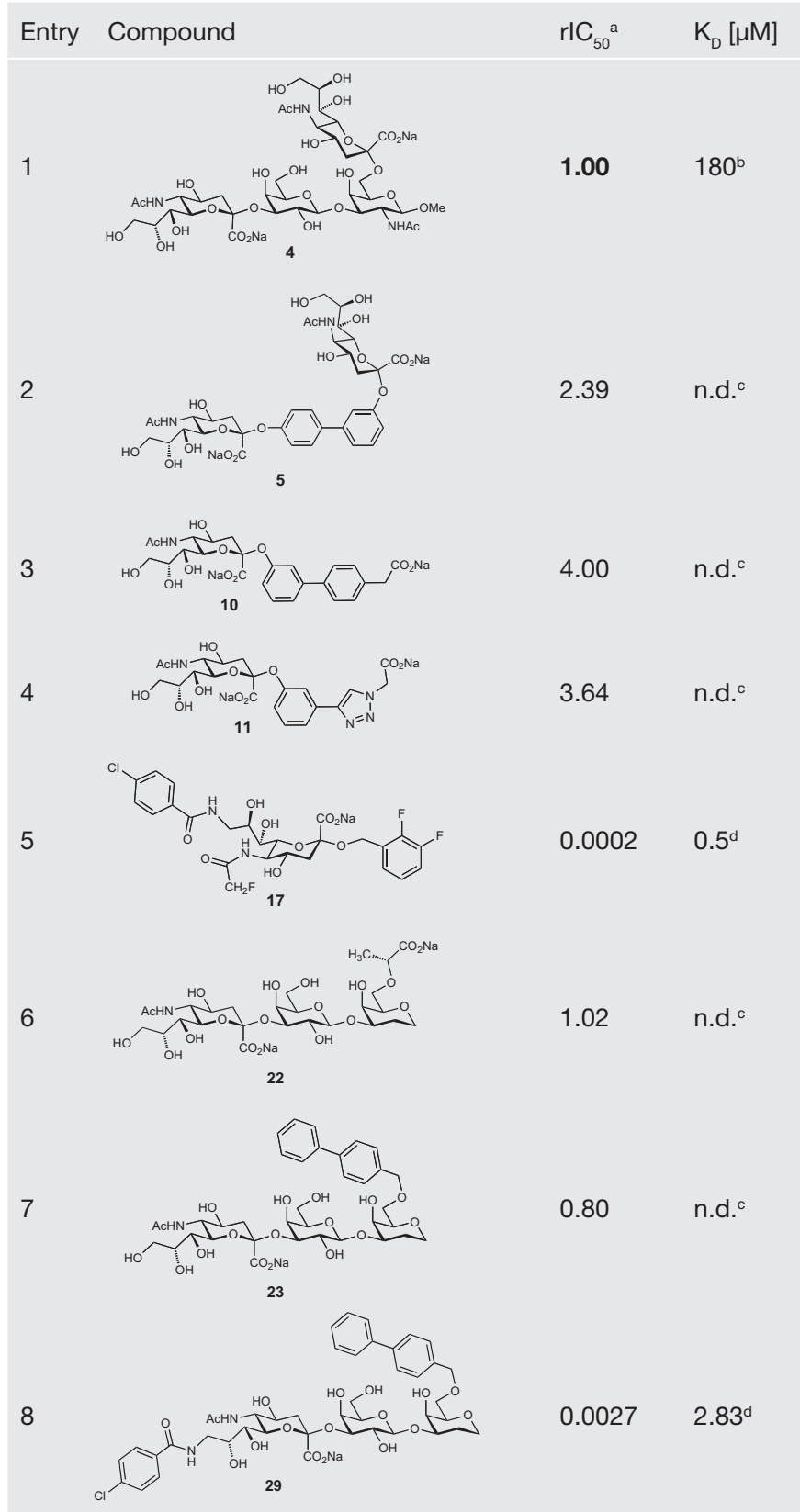

${ }^{a} \mathrm{rlC}_{50}$ is the concentration when $50 \%$ of the protein are inhibited, measured relative to reference compound 4;

${ }^{b}$ determined by STD NMR; ${ }^{\circ}$ n.d. not determined; determined by surface plasmon resonance (Biacore.)

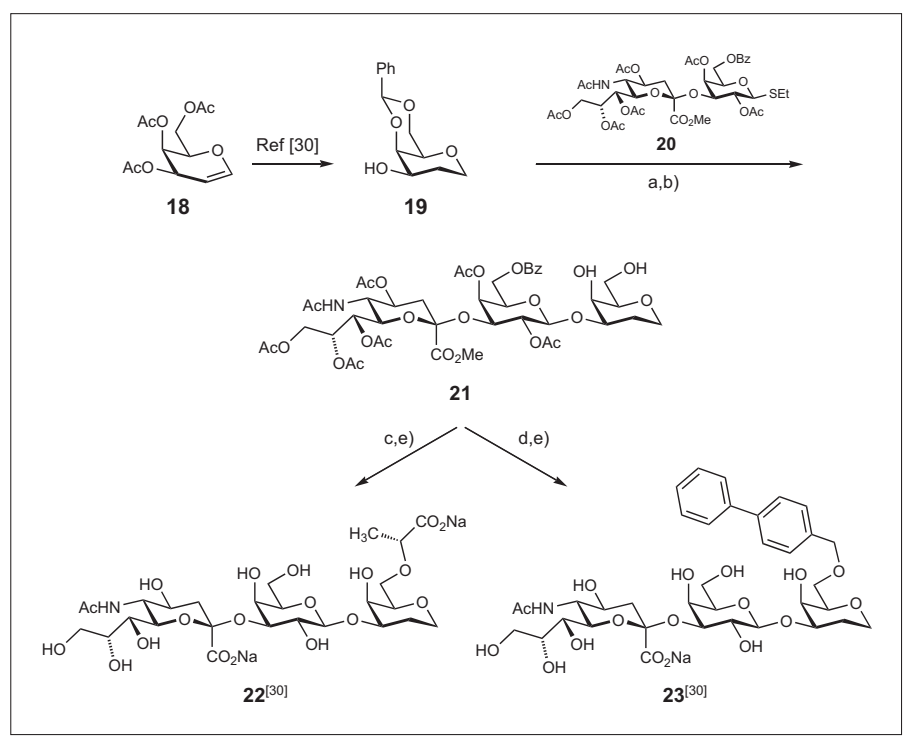

Scheme 3. a) DMTST, MS $3 \AA \AA$, DCM, $0^{\circ} \mathrm{C}, 2$ d, $79 \%$; b) $80 \%$ aq. $\mathrm{AcOH}$ $60{ }^{\circ} \mathrm{C}, 3 \mathrm{~h}, 89 \%$; c) i. $\mathrm{Bu}_{2} \mathrm{SnO}$, benzene, $80^{\circ} \mathrm{C}, 3 \mathrm{~h}$, ii. ethyl (S)-2-O(trifluoromethylsulfonyl)-lactate, CsF, DME, r.t., $1 \mathrm{~d}, 85 \%$; d) i. biphenyl4-carbaldehyde, cat. $p$-TsOH, $\mathrm{MeCN}, 70^{\circ} \mathrm{C}, 4$ h, ii. $\mathrm{Me}_{3} \mathrm{~N} \cdot \mathrm{BH}_{3}, \mathrm{AlCl}_{3}$, THF, r.t., 3 h, $51 \%$; e) $\mathrm{NaOMe} / \mathrm{MeOH}$, r.t., 1 d, then aq. $\mathrm{NaOH}$, rt, 7 h, 22: $68 \%, 23: 96 \%$.

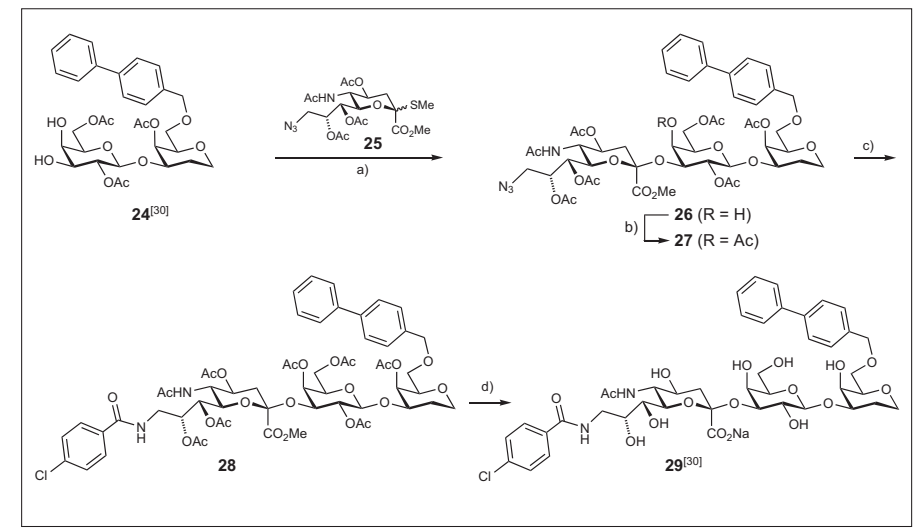

Scheme 4. a) NIS/TfOH, $\mathrm{MeCN},-40^{\circ} \mathrm{C}, 61 \%$; b) $\mathrm{Ac}_{2} \mathrm{O}$, pyr, $80 \%$; c) p-Cl-BzCl, $\mathrm{PPh}_{3}$, DCE, r.t., 16 h, $75 \%$; d) $\mathrm{NaOMe} / \mathrm{MeOH}$, r.t., 3 h, then aq. $\mathrm{NaOH}$, r.t., 16 h, $75 \%$.

$$
\text { d) }
$$

Scheme 2. a) $4 \mathrm{M} \mathrm{PhOH}, 4 \mathrm{M} \mathrm{TMSCl}$ in DCM, $70 \%$; b) FAcCl, NEt ${ }_{3}$, DMAP, DCM, rt, $16 \mathrm{~h}$, $85 \%$; c) 2,3-difluorobenzyl alcohol, NIS, TfOH, MeCN, $\alpha$-isomer: $60 \%$; $\beta$-isomer: $11 \%$; d) $\mathrm{PPh}_{3}, p-\mathrm{Cl}-\mathrm{BzCl}, \mathrm{DCE}$, r.t., $48 \%$; e) $10 \%$ aq. $\mathrm{LiOH}, \mathrm{THF} / \mathrm{H}_{2} \mathrm{O}$; Dowex $50 \times 8\left(\mathrm{Na}^{+}\right), 30 \%$. 


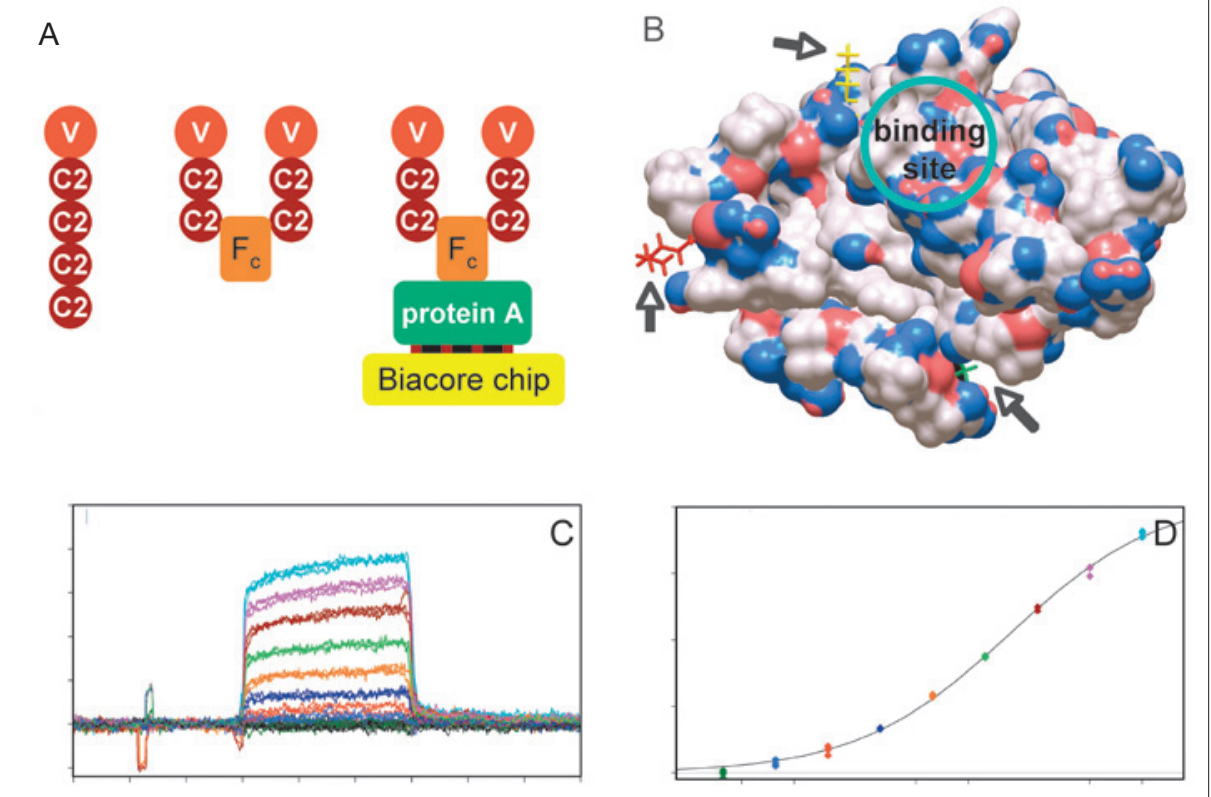

Fig. 5. A) Physiological MAG consisting of a $V$ domain, four consensus repeats, a transmembrane domain and a cytosolic tail. It was expressed as an $\mathrm{Fc}$ conjugate with two $\mathrm{V}$ domains $\left(\mathrm{MAG}_{d 1-3}\right.$ $\left.-\mathrm{Fc}^{[43]}\right)$, allowing a non-covalent immobilization on protein $A$, which on its part was covalently immobilized by amine coupling; B) The V-domain of MAG contains three lysines, one of which is located close to the carbohydrate binding site. Therefore, immobilization on the bioacore chip by amine coupling led to a surface which was not saturable; C) \& D) With this stable surface, Biacore experiments leading to reproducible block signals and $K_{D}$ determination were performed. ${ }^{[41]}$

target compartment of an in vivo application. Furthermore, the $\log \mathrm{D}_{\text {octanol/water }}$ value of -0.26 is beneficial for an intrathecal application, since this distribution coefficient suggests a loss from the CNS compartment by a passive transport mechanism to be unlikely. This hypothesis is further supported by the results of the BBB-PAMPA assay showing a $\log \mathrm{P}$ value of -10 for 17 . For values below -5.7 , no passive permeation through the BBB is expected. ${ }^{[45]}$

\section{Docking of Antagonists to a Homology Model of MAG}

For docking studies of the antagonists 4, 17 and 29, a homology model of MAG based on the three-dimensional structure of sialoadhesin was used. ${ }^{29,30]}$ The ligands were first manually docked to the binding pocket of the MAG model using the salt bridge to $\operatorname{Arg} 118$ and the hydrogen bond of the $9-\mathrm{OH}$ to the backbone carbonyl of Phe129 as anchor points. Next, the protein-ligand complex was minimized in aqueous solution and then subjected to a molecular-dynamics equilibration protocol. The lowest-energy binding modes of tetrasaccharide $\mathbf{4}$ and mimics $\mathbf{1 7}$ and $\mathbf{2 9}$ are compared in Fig. 6.

All three antagonists, tetrasaccharide 4 (Fig. 6A) and the mimics 17 (Fig. 6B) and 29 (Fig. 6C) form salt bridges with Arg118. In addition, the three antagonists establish a crucial hydrophobic interaction between the 5-amido groups and the side chains of

22 and Tyr124. Whereas 4 develops second salt bridge between the carboxylate of the $\alpha(2-6)$-linked Neu5Ac and Lys67, the mimics $\mathbf{1 7}$ and $\mathbf{2 9}$ establish prominent interactions with two hydrophobic pockets. Glu131 and Tyr127 are homing the $p$ chloro benzamide substituent and the side chains of Trp59, Tyr60, Tyr69 and Tyr116 are lining the main hydrophobic pocket and accommodate the 2,3-difluorobenzene $(\rightarrow 17)$ and biphenylmethyl moiety $(\rightarrow 29)$, respectively.

\section{Conclusion}

Overall, with antagonist $\mathbf{1 7}$ the affinity of lead 4 could be improved more than 350 -fold. Its pharmacokinetic properties certify the drug-like properties of the best so far identified MAG antagonist. A further important issue to be addressed is the metabolic stability of the presented oligosaccharide mimics. In general, the substrate specificity of mammalian sialidases is determined by the linkage type of the terminal sialic acid residue (2-3, 2-6 or 2-8) and does not depend on the structure of the underlying oligosaccharide. ${ }^{[46]}$ Therefore, it cannot be excluded that the presented mimics are metabolically cleaved by sialidases. Nevertheless, this new class of MAG blockers constitute an important step toward the development of potent oligosaccharide mimics.

Received: January 20, 2010
[1] M. E. Schwab, C. E. Bandtlow, Nature 1994, $371,658$.

[2] S. Ramon y Cajal, 'Degeneration and Regeneration of the Nervous System', Oxford Univ. Press, London, 1928

[3] M. E. Schwab, P. Caroni, J. Neurosci. 1988, 8 , 2381.

[4] A. Sandvig, M. Berry, L. B. Barrett, A. Butt, A Logan, GLIA 2004, 46, 225.

[5] M. T. Filbin, Nature Rev. Neurosci. 2003, 4, 703.

[6] Z. G. He, V. Koprivica, Ann. Rev. Neurosci. 2004, 27, 341 .

[7] P. Caroni, T. Savio, M. E. Schwab, Prog. Brain Res. 1988, 78, 363 .

[8] R. H. Quarles, Neurochem. Res. 2009, 34, 79.

[9] R. H. Quarles, J. Neurochem. 2007, 100, 1431.

[10] P. R. Crocker, E. A. Clark, M. T. Filbin, S Gordon, Y. Jones, J. H. Kehrl, S. Kelm, N. Le Douarin, L. Powell, J. Roder, R. L. Schnaar, D. C. Sgroi, K. Stamenkovic, R. Schauer, M. Schachner, T. K. van den Berg, P. A. van der Merwe, S. M. Watt, A. Varki, Glycobiology 1998, 8, Glycoforum 2, v.

[11] S. Kelm, A. Pelz, R. Schauer, M. T. Filbin, S Tang, M. E. de Bellard, R. L. Schnaar, J. A. Mahoney, A. Hartnell, P. Bradfield, Curr. Biol. 1994, 4, 965 .

[12] J. Lauren, F. Hu, J. Chin, J. Liao, M. S Airaksinen, S. M. Strittmatter, J. Biol. Chem. 2007, 282, 5715 .

[13] L. A. Robak, K. Venkatesh, H. Lee, S. J. Raiker, Y. Duan, J. Lee-Osbourne, T. Hofer, R. G. Mage, C. Rader, R. J. Giger, J. Neurosci. 2009, 29, 5766.

[14] L. J. S. Yang, C. B. Zeller, N. L. Shaper, M. Kiso, A. Hasegawa, R. E. Shapiro, R. L. Schnaar, Proc. Nat. Acad. Sci. USA 1996, 93 , 814.
[15] S. Tang, Y. J. Shen, M. E. DeBellard, G Mukhopadhyay, J. L. Salzer, P. R. Crocker, M. T. Filbin, J. Cell Biol. 1997, 138, 1355.

[16] M. Vinson, P. J. L. M. Strijbos, A. Rowles, L. Facci, S. E. Moore, D. L. Simmons, F. S. Walsh, J. Biol. Chem. 2001, 276, 20280.

[17] V. Wörter, R. Schweigreiter, B. Kinzel, M Mueller, C. Barske, G. Böck, S. Frentzel, C. E. Bandtlow, PLOS ONE 2009, 4, e5218; doi:10.1371/journal.pone.0005218.

[18] L. J. S. Yang, I. Lorenzini, K. Vajn, A. Mountney, L. P. Schramm, R. L. Schnaar, Proc. Nat. Acad. Sci. USA 2006, 103, 11057.

[19] B. E. Collins, M. Kiso, A. Hasegawa, M B. Tropak, J. C. Roder, P. R. Crocker, R. L. Schnaar, J. Biol. Chem. 1997, 272, 16889.

[20] O. Blixt, B. E. Collins, I. M. van den Nieuwenhof, P. R. Crocker, J. C. Paulson, J. Biol. Chem. 2003, 278, 31007 .

[21] H. Ito, H. Ishida, B. Collins, S. Fromholt, R Schnaar, M. Kiso, Carbohydr. Res. 2003, 338, 1621.

[22] A. A. Vyas, O. Blixt, J. C. Paulson, R. L. Schnaar, J. Biol. Chem. 2005, 280, 16305.

[23] L. Herfurth, B. Ernst, B. Wagner, D. Ricklin, D S. Strasser, J. L. Magnani, A. J. Benie, T. Peters, J. Med. Chem. 2005, 48, 6879 .

[24] S. Shin, H. Gäthje, O. Schwardt, G. Gao, B Ernst, S. Kelm, B. Meyer, ChemBioChem 2008, 9, 2946.

[25] S. V. Shelke, G. P. Gao, S. Mesch, H. Gäthje, S. Kelm, O. Schwardt, B. Ernst, Bioorg. Med Chem. 2007, 15, 4951.

[26] a) E. Bieberich, S. S. Liour, R. K. Yu, Methods Enzymol. 2000, 312B, 339; b) J. Kopitz, K. Sinz, R. Brossmer, M. Cantz, Eur. J. Biochem. 1997, 248, 527.

[27] a) K. Hotta, H. Ishida, A. Hasegawa, $J$. Carbohydr. Chem. 1995, 14, 491; b) H. Ito, H. Ishida, S. Ando, M. Kiso, Glycoconjugate J. 1999, 16, 585; c) N. Sawada, H. Ishida, B. E. Collins, R. L. Schnaar, M. Kiso, Carbohydr. Res. 1999, 316, 1; d) B. E. Collins, H. Ito, N. 

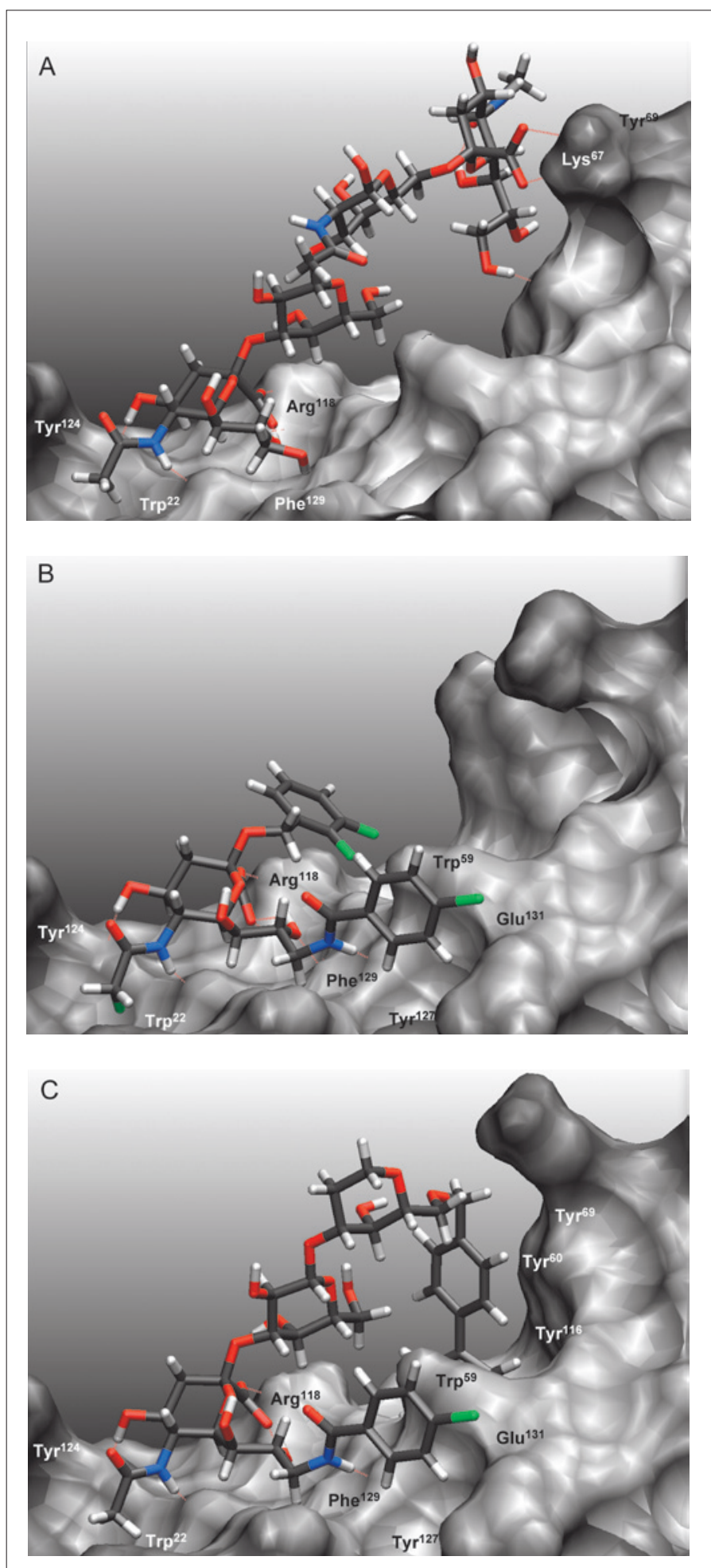

Fig. 6. The three-dimensional structures of 4,17 and 29 were generated using the MacroModel software ${ }^{[31]}$ and optimized in aqueous solution by means of the AMBER ${ }^{*}$ force field. ${ }^{[32]}$ Atomic partial charges (MNDO/ESP) were then generated using MOPAC. ${ }^{[33]}$ The ligands were first manually docked and the protein-ligand complex was minimized in aqueous solution and then subjected to a molecular-dynamics equilibration protocol ( $24 \mathrm{ps}$ at $10 \mathrm{~K}$, heating to $300 \mathrm{~K}$ during $48 \mathrm{ps}, 1 \mathrm{ps}=10^{-12}$ $\mathrm{s})$, followed by a molecular dynamic at $300 \mathrm{~K}$ for $4 \mathrm{~ns}$ performed with Desmond $^{[34]}$ (at 2.4 ps intervals). The structures of the trajectory along the molecular dynamic simulation have been sampled through a hierarchical cluster linkage method at 2.4 ps intervals. The images have been generated using VMD. $\left.{ }^{[35]} \mathrm{A}\right)$ Tetrasaccharide 4 , a substructure of ganglioside GQ1b $\alpha, B)$ antagonist 29; antagonist 17.
Sawada, H. Ishida, M. Kiso, R. L. Schnaar, $J$ Biol. Chem. 1999, 274, 37637; e) H. Ito, H. Ishida, M. Kiso, J. Carbohydr. Chem. 2001, 20, 207.

[28] K. Strenge, R. Schauer, N. Bovin, A. Hasegawa, H. Ishida, M. Kiso, S. Kelm, Eur. J. Biochem. 1998, 258, 677 .

[29] A. Bhunia, O. Schwardt, H. Gäthje, G. Gao, S. Kelm, A. J. Benie, M. Hricovini, T. Peters, B. Ernst, ChemBioChem 2008, 9, 2941.

[30] O. Schwardt, H. Gaethje, A. Vedani, S. Mesch, G. Gao, M. Spreafico, J. von Orelli, S. Kelm, B. Ernst, J. Med. Chem. 2009, 52, 989.

[31] F. Mohamadi, N. G. Richards, W. Guida, R. Liskamp, M. Lipton, C. Caufield, G. Chang, T. Hendrickson, W. C. Still, J. Comput. Chem. 1990, $11,440$.

[32] S. J. Weiner, P. A. Kollmann, D. A. Case, U. C. Singh, C. Ghio, G. Alagona, S. Profeta Jr., P. Weiner, J. Am. Chem. Soc. 1984, 106, 765.

[33] J. J. P. Stewart, J. Comput. Aided Molec. Design 1990, 4,1 .

[34] D. E. Shaw Research, 'Desmond Molecular Dynamics System', 2.0109; New York, NY, 2008.

[35] W. Humphrey, A. Dalke, K. Schulten, J. Molec. Graphics 1996, 14, 33.

[36] D. Schwizer, H. Gäthje, S. Kelm, M. Porro, O. Schwardt, B. Ernst, Bioorg. Med. Chem. 2006 , $14,4944$.

[37] R. Kuhn, P. Lutz, D. L. MacDonald, Chem. Ber 1966, 99, 611.

[38] G. Gao, M. Smiesko, O. Schwardt, H. Gäthje, S. Kelm, A. Vedani, B. Ernst, Bioorg. Med. Chem. 2007, 15, 7459

[39] S. Kelm, R. Brossmer, R. Isecke, H.-J. Gross, K. Strenge, R. Schauer, Eur. J. Biochem. 1998, 255,663 .

[40] S. Kelm, R. Brossmer, PCT Patent WO 03/000709A2, 2003.

[41] S. Mesch, D. Moser, D. S. Strasser, A. Kelm, B. Cutting, G. Rossato, A. Vedani, H. KoliwerBrandl, M. Wittwer, S. Rabbani, O. Schwardt, S. Kelm, B. Ernst, J. Med. Chem. 2010, in press; doi: $10.1021 / \mathrm{jm} 901517 \mathrm{k}$.

[42] P. Boullanger, V. Maunier, D. Lafont, Carbohydr. Res. 2000, 324, 97.

[43] N. Bock, S. Kelm, in 'Methods in Molecular Biology', Vol. 347, Ed. I. Brockhausen, Humana Press Inc, Totowa NJ, 2006, p 359.

[44] R. Mitchell, D. Herbert, C. Carman, J. Appl. Physiol. 1965, 20, 27.

[45] L. Di, E. Kerns, K. Fan, O. McConnell, Eur. J. Med.Chem. 2003, 38, 223.

[46] J. Kopitz, K. Sinz, R. Brossmer, M. Cantz, Eur. J. Biochem. 1997, 248, 527. 